\title{
A diary study of impulsive buying during the COVID-19 pandemic
}

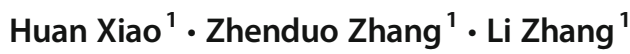 \\ Accepted: 20 November 2020 / Published online: 23 November 2020 \\ (C) Springer Science+Business Media, LLC, part of Springer Nature 2020
}

\begin{abstract}
The purpose of this paper is to explore why impulsive buying happens under emergency and crisis situations, such as that of COVID-19. Drawing on the cognitive-affective personality system theory (CAPS), we tested the dynamic influence of daily perceived uncertainty on COVID-19 on daily impulsive buying via daily information overload and daily information anxiety in a two-wave experience sampling method (ESM) design. Through a multilevel structural equation model (MSEM) analysis, we found that the daily perceived uncertainty on COVID-19 affected daily information overload, which in turn stimulated daily information anxiety, ultimately determining the daily impulsive buying. Namely, daily information overload and daily information anxiety played a complete chain-mediating role between the daily perceived uncertainty on COVID-19 and daily impulsive buying. The present paper is the first to uncover the important dynamic effect of the perceived uncertainty on COVID-19 on impulsive buying with diary data. Specific implications of these findings are discussed.
\end{abstract}

Keywords Impulsive buying $\cdot$ Information overload $\cdot$ Information anxiety $\cdot$ COVID-19 $\cdot$ Pandemic $\cdot$ ESM

\section{Introduction}

In early 2020, a novel pandemic (COVID-19) raged in Wuhan, China, and swiftly spread all over the world, rapidly becoming a worldwide public health emergency (Wang, Peter, Frederick, \& George, 2020a). Since then, billions of people stopped commuting to work or school, avoided social contact, and even isolated themselves at home to prevent the spread of the pandemic (Fischer et al., 2020). Although such prevention and control measures can effectively stop the spread of a pandemic (Remuzzi \& Remuzzi, 2020), they also spawn a series of social governance issues and have negative impacts on general public's mental health (Ahmad \& Murad, 2020; Horton, 2020; Wang et al., 2020c). A systematic review

Huan Xiao and Zhenduo Zhang are both the first author, and contribute equally to this paper.

Li Zhang

zhanglihit@hit.edu.cn

Huan Xiao

19B910058@stu.hit.edu.cn

Zhenduo Zhang

zhangzhenduo12@mails.ucas.ac.cn

1 School of Management, Harbin Institution of Technology, 13 Fayuan Street, Nangang District, Harbin 150001, Heilongjiang, China has proved that the COVID-19 is truly associated with psychology distress worldwide, such as anxiety and stress (Xiong et al., 2020), which may cause impulsive buying (Deng, Wang, Xie, Chao, \& Zhu, 2020).

In fact, a notable phenomenon observed in the current COVID-19 pandemic was exactly that general pubic bought or hoarded of a mount of face masks since China encouraged the usage of face masks to protect their health during the COVID-19 pandemic (Wang et al., 2020b). Similarly, the public engaged into an impulsive buying even though they had already a large quantity of items, thereby causing a significant shortage of masks, alcohol, and other medical supplies (Huang \& Zhao, 2020). For example, the fake news that the "Shuanghuanglian oral liquid" could suppress COVID-19 (People's daily of China, 2020) was madly forwarded across social media platforms in China. As a result, this drug was immediately sold out overnight.

This impulsive buying has caused a serious shortage of emergency supplies and intensified public panic (Sim, Chua, Vieta, \& Fernandez, 2020). Therefore, it is necessary to further investigate the phenomenon of impulsive buying in emergency and crisis situations. However, there is a limited number of studies on this issue (Thomas \& Monica, 2002; Chow \& Elkind, 2005; Deng et al., 2020), which mainly adopted a qualitative approach and lack empirical evidence. In addition, no empirical research has discussed the internal mechanism of impulsive buying in emergency and crisis situations. 
The phenomenon of impulsive buying did not occur for the first time in China, as it often accompanies public emergency and crisis events (such as, for example, the SARS epidemic and influenza A-H1N1). However, it was especially amplified during the current COVID-19 pandemic compared to previous epidemics, due to the rapid development of the Internet and social media. Today, people could access to an almost endless stream of information related to COVID-19, even can share news, reports, and their own feelings and experiences related to COVID-19 via various forms of online platforms and social medias (Sharma, Yadav, Yadav, \& Ferdinand, 2017). Therefore, the COVID-19 pandemic provides a unique opportunity to investigate the role of the Internet information in increasing uncertainty and crazy impulsive buying.

To address these research gaps, we conducted a multi-wave diary study to explore the internal psychological mechanism of impulsive buying under the uncertainty situation generated by the COVID-19. We focused on the daily, within-individual consequences of the uncertainty on COVID-19 given the "ongoing, dynamic, and time-dependent" nature of this emergency event (Morgeson, Mitchell, \& Liu, 2015; Wang et al., 2020d). To develop our framework, we drew on the cognitive-affective personality system theory (CAPS; Mischel \& Shoda, 1995, 1998), as it is a broad theoretical model that focuses on the dynamic within-individual variation in response to experienced events (Cervone, 2005). Based on the CAPS theory, we constructed a chain mediation model in which the perceived uncertainty on COVID-19 affects citizens' impulsive buying behaviors. More in detail, the external event (i.e., the uncertainty on COVID-19) will affect citizens' cognition (e.g., information overload), and thus affect their emotions (e.g., information anxiety), ultimately determining the resulting behavior (i.e., impulsive buying; Lavelle, Rupp, \& Brockner, 2007; Yao, Zhang, Luo, \& Huang, 2020). The theoretical model is shown in Fig. 1.

In doing so, the present study aims to make three main theoretical contributions to existing literature. First, we provided empirical evidence of the impulsive buying phenomenon under emergency and crisis situations, such as in the case of the COVID-19 pandemic. Moreover, based on the CAPS theory, we put forward two chain mediators (i.e., information overload and information anxiety) to clarify the psychological mechanism of impulsive buying, so as to strengthen the understanding of impulsive buying during the COVID-19 pandemic. Finally, as the relatively limited number of studies on COVID-19 adopted a between-persons approach, which shows how individuals differ from one another, and which did not fully account for the fluctuation of COVID-19 pandemic over time (Mccormick, Reeves, Downes, Li, \& Ilies, 2020; Sonnentag, 2012). Hence, we used the experience sampling method (ESM) to shed light on the important dynamic influence of the daily perceived uncertainty on COVID-19 on determining individual daily impulsive buying. These contributions will enrich the literature on emergency management and extend the application of the CAPS theory on impulsive buying research. Moreover, they may support the development of strategies to reduce anxiety and impulsive buying caused by social media usage during the COVID-19 pandemic.

\section{Theoretical Background and Hypotheses Development}

\section{Perceived Uncertainty on COVID-19 and Information Overload}

Information overload represents a state in which a person lacks cognitive resources, due to receiving a large amount of information and failing to properly process it within a certain period of time (Eppler \& Mengis, 2004; Liu, 2014). Since the origin of information dissemination, information is mainly used to eliminate uncertainty in people's perception of the external world (Shannon, 1948). During the outbreaks and public health emergencies, such as the COVID-19 pandemic, the public experiences uncertainty and, therefore, is very concerned about safety issues (Xiang et al., 2020). Le et al. (2020) found that the public constantly follows and updates health information on the outbreak, the disease symptoms, and the instructions about preventing transmission. As reported in the news, people were worried every day, especially at the beginning of the outbreak. They were afraid that they did not have enough information to protect themselves and their family. In order to fully understand the pandemic, they even downloaded several news apps on their mobile phones, followed several public accounts or related bloggers, constantly browsing, forwarding, and sharing information in all kinds of social medias every day (Chongqing Evening News, 2020). However, the overburdening stream of information could not reduce panic. On the contrary, information overload may occur when people struggle to keep up with a seemingly endless stream of incoming information, as in the case of COVID-19, and they
Fig. 1 Indicates the conceptual research model of the present study

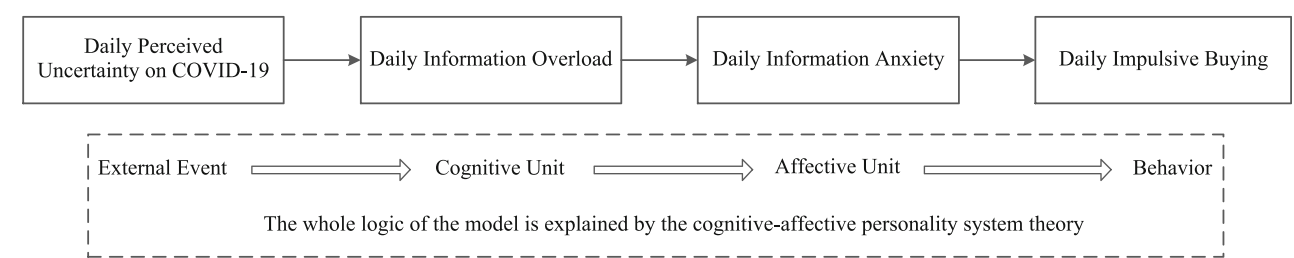


interact with others online permanently, especially when they are unable to follow the updates in real time and need to catch up later on what they have potentially missed (Lee, Son, \& Kim, 2016; Matthes, Karsay, Schmuck, \& Stevic, 2019). As Smith, Ostinelli, and Cipriani (2020) argued, there has been an issue of information overload during the COVID-19 pandemic, and it was difficult and time-consuming to obtain reliable and up-to-date information within a 'sea' of information.

In addition to information quantity, information quality is also an important factor inducing information overload, whereby the redundancy in the quantity of information is accompanied by a decline in the quality of information (Schmitt, Debbelt, \& Schneider, 2017). Tran et al. (2020a) found that the public access their COVID-19 information more through the online mass media (e.g., phone-based applications, online newspapers, social networks) than through official channels. While the Internet and social media in the era of globalization have facilitated the explosive production and dissemination of misinformation, fake news or rumors (Sommariva, Vamos, Mantzarlis, Đào, \& Martinez Tyson, 2018), standing as another manifestation of information overload. This phenomenon is also called "infodemic", and has accompanied the COVID-19 outbreak according to the World Health Organization (Hua \& Shaw, 2020). "Infodemic", i.e., an over-abundance of information, some of which is accurate and some of which is not, hampers the capacity of people to find trustworthy sources and reliable guidance in case of need (Zarocostas, 2020), which makes it easier to causing information overload. Accordingly, at times of considerable uncertainty, such as during the COVID-19 pandemic, an increased amount of cases of information overload can be expected to emerge. Based on these considerations, we advanced the following hypothesis:

Hypothesis 1. The daily perceived uncertainty on COVID19 had a positive impact on daily information overload.

\section{Information Overload and Information Anxiety}

Prior research found that information overload can lead to a wide range of negative consequences, such as negative affect (Benselin \& Ragsdell, 2016; LaRose, Connolly, Lee, Li, \& Hales, 2014; Primack et al., 2017), fatigue (Hwang, Hong, Tai, Chen, \& Gouldthorp, 2019; Lee et al., 2016), psychological ill-being (Misra \& Stokols, 2012; Swar, Hameed, \& Reychav, 2017), exhaustion (Cao \& Sun, 2018), lowered self-esteem (Chen \& Lee, 2013), and decreasing control (Heylighen, 2002). During the COVID-19 pandemic, the use of the Internet and social media flourished and favored an explosive growth in the amount of information available. People had difficulties to absorb, process, and digest this redundant and unreliable information, resulting in anxiety, irritability, panic, powerlessness, and a self-compulsion mental state (Bawden \& Robinson, 2009). This state is called information anxiety, and is the manifestation of the brain's resistance to adapt to low-quality information.

Information anxiety is conceptualized as a negative affective response to situations where people face a massive amount of information but cannot understand and digest it, and have difficulties in finding the information they need (Wurman, 1989). Arnold (1960) argued that the cognitive evaluation of specific stimulus events determines the emotional response. During the COVID-19 pandemic, a large quantity of similar, ambiguous, or false information has become one of the main factors affecting public mood (Matthes et al., 2019; Ping, 2013), and provided objects for their cognitive evaluation. The results of this evaluation will generate psychological changes into the public (Siemer, Gross, \& Mauss, 2007), leading people to deviate from a normal emotional state (Moors, Ellsworth, Scherer, \& Frijda, 2013), one of the significant manifestations of which is information anxiety. In other words, information overload may disrupt cognitive reasoning ability and weaken attentional resources, leading to the incapacity for people to distinguish between true or fake information and, therefore, increasing their information anxiety. Additionally, people always pay more attention to searching and focusing on the most severe and worst news first. As such, the level of information anxiety may heighten while people suffer from information overload (Hwang et al., 2019).

Generally, information overload sends signals to individuals, warning them that they cannot meet the information processing demands of the environment when facing a large amount of redundant and poorly reliable information. This can cause a series of unconscious tensions and anxiety. However, despite consistent empirical evidence indicating that information overload is positively related to anxiety, the dynamic of this relationship over time has never been tested longitudinally. Therefore, we proposed the following hypothesis:

Hypothesis 2. Daily information overload has a positive impact on daily information anxiety.

\section{Information Anxiety and Impulsive Buying}

Impulsive buying has been loosely defined in literature as spontaneous, immediate, and unplanned purchase (D'Antoni Jr \& Shenson, 1973; Rook \& Fisher, 1995; Stern, 1962), often triggered by stimuli (Rook, 1987). Prior research found that impulsive buying is driven by a variety of psychological factors, such as affect, or affective state (Bellini, Cardinali, \& Grandi, 2017; Mohan, Sivakumaran, \& Sharma, 2013; Verplanken et al., 2005), impulse tendency (Lucas \& Koff, 2017; Nagar, 2016), self-esteem (Bandyopadhyay, 2016), 
self-identity and self-image (Lucas \& Koff, 2017), upward social comparison ( $\mathrm{Liu}, \mathrm{He}, \& \mathrm{Li}, 2019$ ), long-term orientation (Aparecida Lehmann, Krug, \& Falaster, 2019), and aspects of the big five personality factors (Bratko, Butkovic, \& Bosnjak, 2013).

By reviewing the extant literature, it can be clearly found that impulsive buying is an emotion-related behavior. According to the CAPS framework, affect is a key antecedent of impulsive buying, since individual's affect plays an important role in the subsequent behavioral response. Prior research agrees on the positive effect of positive affect on impulsive buying (Bellini et al., 2017; Mohan et al., 2013). However, studies of the role of negative affect in impulsive buying have led to inconsistent results. For instance, based on Indian samples, Mohan et al. (2013) found that the relationship between negative affect and impulsive buying is not significant. Both Bandyopadhyay (2016) and Liu et al. (2019) confirmed that negative affect can stimulate impulsive buying, while Bellini et al. (2017) indicated that negative affect may inhibit impulsive buying. Hence, further examination of this issue is imperative, in view of these contradictory empirical evidences.

Additionally, in a specific emergency and crisis context, such as in the case of COVID-19, information anxiety could be a kind of typical negative affect experienced by the public. In the case of COVID-19, people were highly stressed, and information anxiety could have led to cognitive and emotional resources shortage, such that it was difficult for people to process different types of information at the same time. In these cases, people usually act as if they are overwhelmed, and tend to engage into impulsive buying as a way to comfort themselves (Müller et al., 2012). This phenomenon can be explained also by the coping theory (Lazarus \& Folkman, 1984), according to which individuals may employ an impulsive buying behavior to temporarily cope with, and block out, their undesirable, negative affect states, such as information anxiety (Yi, 2012). As indicated by Valence, D'Astous, and Fortier (1988), consumer anxiety is central to impulsive buying. Therefore, we proposed the following hypothesis:

Hypothesis 3. Daily information anxiety has a positive impact on daily impulsive buying.

\section{The Chain Mediating Effect}

According to the CAPS theory, the cognitive-affective units of an individual are the key drivers between external events and subsequent behaviors (Lavelle et al., 2007). When an individual faces a certain event or situation, a specific cognitive emotional unit will be activated to appraise and respond to this event, and to determine the ultimate behavior (Mischel \& Shoda, 1995). Moreover, the CAPS theory emphasizes that the cognitive and affective units are not isolated and static, but affect each other to form a dynamic personality network system. In other words, the external events will influence individual behavior by activating cognitive units, which in turn arouse affective units (Lee \& Pee, 2015; Yao et al., 2020). According to prior literature, information overload occurs when the limited amount of cognitive resources cannot allow individuals to process all information inputs; it belongs to the cognitive units in the personality network system (Eppler \& Mengis, 2004; Hwang et al., 2019; Liu, 2014). In a similar way, information anxiety refers to a negative affective state, in which a person faces a massive amount of information that cannot be found, understood, digested, and coped with easily (Bawden \& Robinson, 2009; Wurman, 1989). Accordingly, information anxiety is a typical affective unit in the personality network system.

Therefore, according to the mechanism of the CAPS theory, when individuals perceived uncertainty in relation to the COVID-19 pandemic, their concern about the uncertainty would urge them to continuously search relevant information, seriously consuming their limited cognitive resources, and leading to information overload (Farooq, Laato, \& Akam, 2020; Hua \& Shaw, 2020). The negative cognition that their own resources were being severely depleted and threatened would continue to stimulate their negative emotions, such as anxiety and uneasiness (Moors et al., 2013). Therefore, individuals' information anxiety may be triggered by the perceived information overload (Hwang et al., 2019). In turn, the individuals exposed to information anxiety would be engaged in impulsive buying (Liu et al., 2019; Yi, 2012). In summary, the perceived uncertainty on COVID-19 (external event) would stimulate information anxiety (affective units) by arousing information overload (cognitive units), ultimately driving impulsive buying (behaviors). We therefore proposed the following hypothesis:

Hypothesis 4. Daily information overload and daily information anxiety played a chain-mediating role between the daily perceived uncertainty on COVID-19 and daily impulsive buying; that is, the daily perceived uncertainty on COVID-19 could aggravate the daily information anxiety of individuals by increasing their daily information overload, thereby leading to the impulsive buying behavior.

\section{Methods}

\section{Participants and Procedure}

The present study took place between February 21 and February 28, 2020. As the aim of the study was to investigate 
consumption behavior through an online survey, the following inclusion criteria were established: (1) adults living in mainland China; (2) adults who have their own mobile device connected to the Internet; and (3) adults who have a fixed monthly income. In order to ensure a sufficient sample recovery rate, convenient sampling has been used in the majority of the studies which that applied the ESM design to collect daily data design to collect daily data (e.g., Du et al., 2018; Qin, Huang, Johnson, Hu, \& Ju, 2018). As the present research was performed during the COVID-19 pandemic, the convenient sampling method was employed to recruit participants according to the process proposed by Du, Derks, and Bakker (2017). Through researchers' own social network, we first recruited three Master of Public Administration (MPA) students who were working as human resource managers in their organizations from a university in Jiangxi Province in China to assist in the study. Then, recruitment advertisements were distributed with their help, ultimately yielding 150 confirmed participants in the study.

Then, the 150 participants initially identified were invited to join a WeChat group, which was a convenient tool to remind participants to fill in the survey and send them the questionnaire links. The data collection was performed in two stages. The first stage took place on February 21, 2020. The participants completed a baseline questionnaire assessing gender, age, monthly income, and health status. The second stage was performed from the following Monday to Friday. During this period, participants received a prompt on their smartphones two times per day, one in the morning at 11:00 a.m., when the participants were asked to assess their perceived uncertainty on COVID-19 and information overload, and one in the evening at 5:00 p.m., aimed to assess information anxiety and impulsive buying. Each assessment lasted approximately two minutes, and participants had to answer the prompt within three hours, after which it expired. The sum of $25 \mathrm{RMB}(\approx 3.55 \mathrm{USD})$ was given as compensation to the participants who contributed during all five days; only the data of these participants were retained for the following analyses.

Out of the 150 initially recruited participants, 136 completed the baseline survey, and 109 completed the daily diary survey, with a daily response rate of $80.15 \%$. We eliminated four participants from the sample because their questionnaires were invalid, as excessive items were missing or the same option was ticked consecutively for the vast majority of questions. The final number of valid observations was 525 (i.e., 105 Participants $\times 5$ Days).

The final sample was composed for $43.80 \%$ by females and for $56.20 \%$ by males; the majority of participants were aged $26-35$ years and $36-45$ years $(43.80 \%$ and $33.30 \%$ of the total, respectively). Regarding income, $44.80 \%$ of the participants had a monthly income of $3000 \mathrm{RMB}$ or lower, $30.50 \%$ of $3000-5000 \mathrm{RMB}$, and $24.80 \%$ of over $5000 \mathrm{RMB}$. In terms of health status, only 13 participants reported having suffered from medical health problems in the past, or having taken drugs continuously (12.38\%).

\section{Measures}

The questionnaires were conducted in Chinese; items were adapted to the daily measurement and back-translated following the procedure recommended by Brislin (1980). Unless noted otherwise, all items were rated on a seven-point Likert-type scale, ranging from $1=$ fully disagree to $7=$ fully agree.

Daily perceived uncertainty on COVID-19: We measured this construct in the morning survey with four items, adapted from the event novelty scale used in prior work to assess whether participants have rules or procedures in place to respond to an event (Morgeson, 2005; Morgeson et al., 2015). The adapted four-items instrument allowed to assess the extent to which responding to the COVID-19 was clear to people. Sample items included the following: "Today, there is a clear, known way to cope with COVID-19" and "Today, there is an understandable sequence of steps that can be followed by people to respond to COVID-19". This scale was reversecoded so that higher numbers indicated greater perceived uncertainty on COVID-19. The average internal consistency reliability for the scale was .70 .

Daily information overload: We assessed daily information overload in the evening survey using the three-item measure proposed by Matthes et al. (2019). An example item was the following: "Today, I am distracted by the excessive amount of information on multiple channels/sources about COVID-19". The average reliability for daily information overload was $\alpha=.91$.

Daily information anxiety: Daily information anxiety was measured in the evening survey using four items adapted from Thatcher and Perrewe (2002). Example items were as follows: "Today, I feel apprehensive after reading online information on the COVID-19" and "Today, reading the online information related to COVID-19 is somewhat intimidating to me". The scale yielded an average Cronbach's $\alpha=0.84$.

Daily impulsive buying: We measured the daily impulsive buying of medical supplies due to the COVID-19 emergency in the evening survey. In relation to medical supplies consumption, the participants were asked to indicate their agreement to three items, adapted from He, Kukar-Kinney, and Ridgway (2018). A sample item was the following: "Today, I bought medical supplies I did not plan to buy". The average Cronbach's $\alpha$ was .86.

Control variables: In the baseline survey, we controlled the participants' demographic characteristics including gender, age, and monthly income, as prior research noted that these variables always impact impulsive buying behavior (He et al., 2018; Liu et al., 2019; Vohs \& Faber, 2007). In addition, the 
health status was also controlled, as a good health status could have affected the emotions and behavior of participants during the COVID-19 pandemic (Fischer et al., 2020).

\section{Results}

\section{Validity, Reliability and Correlations}

As shown in Table 1, all the values of the Cronbach's $\alpha$ were higher than 0.70 , demonstrating that the measures of the constructs were reliable. In addition, all the values of composite reliability (CR) surpassed the recommended standard of 0.70 , while all the average variance extracted (AVE) coefficients exceeded the critical value of 0.50 , thereby proving that the convergent validity of our scale was acceptable (Hair, Black, Babin, \& Anderson, 2010). Finally, all the diagonal data (i.e., the square root values of AVE) were greater than their corresponding non-diagonal data (i.e., correlation coefficients), thereby indicating that the discriminant validity of the measurement was achieved (Fornell \& Larcker, 1981).

Table 1 also shows the mean, standard deviation, and correlation coefficient of the focal variables at both within-person and between-person levels. We found a positive and significant relationship between the daily perceived uncertainty on COVID-19 and daily information overload $(\mathrm{r}=0.42, p<.01)$, as well as between daily information overload and daily information anxiety $(r=0.16, p<.01)$, and between daily information anxiety and daily impulsive buying $(r=0.68, p<.01)$. On the contrary, the correlation between daily information overload and daily impulsive buying was not significant $(\mathrm{r}=0.06$, $\mathrm{ns})$.

\section{Multilevel Confirmatory Factor Analysis}

We employed the multilevel confirmatory factor analysis (MCFA) in the Mplus software, Version 7.0 (Muthén \&
Muthén, 2010) to test the measurement model (see Table 2). All the latent factors were modeled using item-level indicators. The four-factors measurement model was a better fit to data $\left(\chi^{2} / \mathrm{df}=2.73, p<.01, \mathrm{RMSEA}=.06, \mathrm{RMR}=.03\right.$, $\mathrm{CFI}=.97$, TLI $=.95)$, as compared to all alternative nested models $\left(\Delta \chi^{2} \geq 67.77, \Delta \mathrm{df} \geq 3\right)$. These results demonstrated that our focal constructs were distinct from each other.

\section{Analysis Strategy}

Since the data were collected through the ESM, we used the hierarchical linear modeling (HLM Version 6.08) to test our hypotheses (Raudenbush, Bryk, Cheong, Congdon, \& du Toit, 2011). Before testing the hypotheses, we investigated systematically the within-person and between-person variance of the daily variables. The within-person variance of the daily variables ranged between $0.79-0.88$. This suggests that a considerable portion of variance in all daily variables was nested at the between-person level, thus justifying the use of the hierarchical linear analysis. All the within-person variables were group-centered. Then, following the suggestion of Roesch et al. (2010), we examined the whole model through the multilevel structural equation model (MSEM) analysis, using the Mplus software (Version 7.0). Following Preacher, Zyphur, and Zhang (2010) and Bliese, Maltarich, and Hendricks's (2018) recommendations, we also used the Monte Carlo method to estimate the confidence intervals for the hypothesized multilevel indirect effects.

\section{Hypotheses Tests}

The hypotheses advanced in this study were tested through the multilevel mediation analysis using the HLM software. The results of the hierarchical linear regression analysis are shown in Table 3. The result of model 2 indicates that the daily perceived uncertainty on COVID-19 positively affected daily

Table 1 Discriminant validity, reliability, and correlations

\begin{tabular}{|c|c|c|c|c|c|c|c|c|c|}
\hline Within-Person $(N=525)$ & $\alpha$ & $C R$ & $A V E$ & Mean & $S D$ & 1 & 2 & 3 & 4 \\
\hline 1. Impulsive Buying & 0.86 & 0.87 & 0.69 & 2.73 & 1.40 & $(0.83)$ & & & \\
\hline 2. Perceived Uncertainty on COVID-19 & 0.70 & 0.71 & 0.55 & 4.10 & 0.84 & 0.01 & $(0.74)$ & & \\
\hline 3. Information Overload & 0.91 & 0.85 & 0.67 & 4.00 & 0.38 & 0.06 & $0.42^{* * *}$ & $(0.82)$ & \\
\hline 4. Information Anxiety & 0.84 & 0.86 & 0.64 & 2.45 & 1.25 & $0.68^{* * *}$ & 0.07 & $0.16^{* *}$ & $(0.80)$ \\
\hline Between-Person $(N=105)$ & & & & Mean & $S D$ & 1 & 2 & 3 & 4 \\
\hline 1. Gender & & & & - & - & & & & \\
\hline 2. Monthly Income & & & & - & - & -0.34 & & & \\
\hline 3. Healthy Status & & & & 1.12 & 0.33 & 0.07 & -0.07 & & \\
\hline 4. Age & & & & - & - & -0.47 & 0.53 & 0.15 & \\
\hline
\end{tabular}

$\alpha=$ Cronbach's alpha; $C R=$ composite reliability; $A V E=$ average variance extracted. The square root values of $A V E$ are presented in parenthesis. For age: $1=8-25 ; 2=26-35 ; 3=36-45 ; 4>=46$. For gender: $1=$ male; $2=$ female. For monthly income: $1<=2500 ; 2=2000-3000 ; 3=3000-5000 ; 4>=$ 5000. $* p<.05, * * p<.01$, two-tailed 
Table 2 Results of the Multilevel Confirmatory Factor Analysis

\begin{tabular}{|c|c|c|c|c|c|c|c|c|}
\hline Model & Variables & $\mathcal{X}^{2}$ & $d f$ & ${ }^{\Delta} \chi^{2}$ & $R M S E A$ & $C F I$ & $T L I$ & $R M R$ \\
\hline Four-Factor Model & PU, IO, IA, IB & 131.16 & 48 & & 0.06 & 0.97 & 0.95 & 0.03 \\
\hline Three-Factor Model 1 & $\mathrm{PU}+\mathrm{IO}, \mathrm{IA}, \mathrm{IB}$ & 201.28 & 51 & $70.12 * *$ & 0.08 & 0.94 & 0.92 & 0.04 \\
\hline Three-Factor Model 2 & $\mathrm{PU}+\mathrm{IA}, \mathrm{IO}, \mathrm{IB}$ & 414.84 & 51 & $283.68 * *$ & 0.12 & 0.85 & 0.80 & 0.14 \\
\hline Three-Factor Model 3 & $\mathrm{PU}+\mathrm{IB}, \mathrm{IO}, \mathrm{IA}$ & 482.29 & 51 & $351.13 * *$ & 0.13 & 0.82 & 0.76 & 0.16 \\
\hline Three-Factor Model 4 & PU, IO+IA, IB & 1205.83 & 51 & $1074.67 * *$ & 0.21 & 0.51 & 0.36 & 0.27 \\
\hline Three-Factor Model 5 & $\mathrm{PU}, \mathrm{IO}+\mathrm{IB}, \mathrm{IA}$ & 1084.97 & 51 & $953.81 * *$ & 0.20 & 0.56 & 0.43 & 0.25 \\
\hline Three-Factor Model 6 & $\mathrm{PU}, \mathrm{IO}, \mathrm{IA}+\mathrm{IB}$ & 198.93 & 51 & $67.77 * *$ & 0.07 & 0.94 & 0.92 & 0.04 \\
\hline One-Factor Model & $\mathrm{PU}+\mathrm{IO}+\mathrm{IA}+\mathrm{IB}$ & 1119.45 & 54 & $988.29 * *$ & 0.19 & 0.55 & 0.45 & 0.21 \\
\hline
\end{tabular}

$\mathrm{N}=525 ; * p<.05, * * p<.01 ; \mathrm{PU}=$ Perceived Uncertainty on COVID-19; IO = Information Overload; IA = Information Anxiety; IB = Impulsive Buying

information overload $(\gamma=0.19, p<.01)$, thereby supporting Hypothesis 1 . According to model 3 , there was a significantly positive relationship between daily information overload and daily information anxiety $(\gamma=0.37, p<.05)$, thus providing support for Hypothesis 2. Also, model 4 showed a positive effect of daily information anxiety on daily impulsive buying $(\gamma=0.71, \mathrm{p}<.01)$, thereby supporting Hypothesis 3 . Thus, these results support the possibility of an indirect effect of the daily perceived uncertainty on COVID-19 on daily impulsive buying, through daily information overload and daily information anxiety.

A MSEM was applied to test the whole conceptual model; the results are presented in Fig. 2. It can be seen that the relationships between our focus variables is almost consistent with the above-mentioned results of the hierarchical linear regression, thereby showing the robustness of the focus variable relationships.
Furthermore, the Monte Carlo bootstrapping procedure with 20,000 replications was run to test the chain mediation model. The indirect effect of the daily perceived uncertainty on COVID-19 on daily information anxiety through daily information overload was significant (effect $=0.07,95 \%$ $\mathrm{CI}=[0.02,0.13])$. Moreover, the chain-mediated effect of daily information overload and daily information anxiety was significant (effect $=0.05,95 \% \mathrm{CI}=[0.01,0.09]$ ). Thus, Hypothesis 4 was also supported (Table 4).

\section{Discussion}

\section{Theoretical Implications}

The present study provides several theoretical contributions to the impulsive buying literature, emergency and crisis management literature, and CAPS theory literature. First, it provided
Table 3 Results of the Hierarchical Regression Analysis

\begin{tabular}{|c|c|c|c|c|c|c|c|c|}
\hline \multirow[t]{3}{*}{ Variables } & \multicolumn{4}{|c|}{ Information Overload } & \multirow{2}{*}{\multicolumn{2}{|c|}{$\begin{array}{l}\text { Information } \\
\text { Anxiety }\end{array}$}} & \multirow{2}{*}{\multicolumn{2}{|c|}{$\begin{array}{l}\text { Impulsive } \\
\text { Buying } \\
\text { Model } 4\end{array}$}} \\
\hline & \multicolumn{2}{|c|}{ Model 1} & \multicolumn{2}{|l|}{ Model 2} & & & & \\
\hline & $\gamma$ & SE & $\gamma$ & SE & $\gamma$ & SE & $\gamma$ & $\mathrm{SE}$ \\
\hline Intercepts & 4.05 & 0.13 & 4.05 & 0.13 & 2.75 & 0.45 & 3.4 & 0.47 \\
\hline \multicolumn{9}{|l|}{ Between-Person $(\mathrm{N}=105)$} \\
\hline Gender & 0.02 & 0.04 & 0.02 & 0.04 & -0.04 & 0.14 & -0.25 & 0.14 \\
\hline Monthly Income & 0.01 & 0.02 & 0.01 & 0.02 & 0.06 & 0.08 & 0.15 & 0.09 \\
\hline Healthy Status & -0.02 & 0.05 & -0.02 & 0.05 & 0.08 & 0.18 & 0.09 & 0.22 \\
\hline Age & -0.03 & 0.03 & -0.03 & 0.03 & -0.18 & $0.09^{*}$ & $-0.3^{* *}$ & 0.09 \\
\hline \multicolumn{9}{|l|}{ Within-Person $(n=525)$} \\
\hline $\begin{array}{l}\text { Perceived Uncertainty on } \\
\text { COVID-19 }\end{array}$ & & & $0.19^{* * *}$ & 0.03 & -0.08 & 0.77 & -0.09 & 0.07 \\
\hline Information Overload & & & & & $0.37^{*}$ & 0.17 & -0.18 & 0.15 \\
\hline Information Anxiety & & & & & & & $0.71^{* *}$ & 0.03 \\
\hline
\end{tabular}




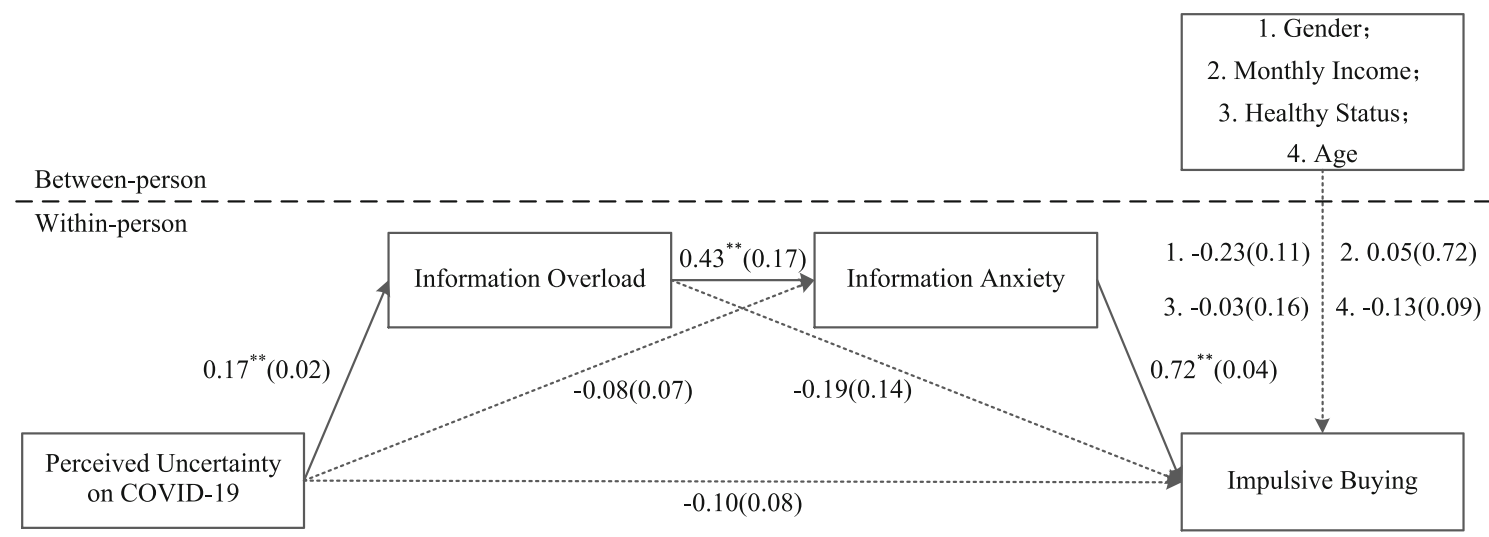

Fig. 2 Is the result of multilevel structural equation model analysis. (1) $\mathrm{N}=105$ at the between-person level; $\mathrm{N}=525$ at the within-person level. (2) Path parameters are standardized, and values in the parenthesis are standard errors. $(3)^{*} p<0.05,{ }^{* *} p<0.01$, two tailed

important advancements with respect to the literatures of impulsive buying. In fact, to our knowledge, we offered the first empirical evidence of how impulsive buying happens under emergency and crisis situations, using the COVID-19 pandemic as an example. The literature review that was performed, showed that neither the relationship, nor the influence mechanism of uncertainty under specific emergency and crisis situations on impulsive buying has been previously discussed. We concluded that daily uncertainty triggers individual's daily impulsive buying during a pandemic such as COVID-19, thereby extending the antecedents of impulsive buying. The antecedents and consequences of impulsive buying have been explored in a large number of domains; however, few researchers paid attention to specific emergency and crisis situation. The results of the present study are in line with the

Table 4 Results of the Monte Carlo Bootstrapping Test

\begin{tabular}{|c|c|c|c|c|}
\hline \multirow[t]{2}{*}{ Paths } & \multirow[t]{2}{*}{ Estimator } & \multirow[t]{2}{*}{ SE } & \multicolumn{2}{|l|}{$95 \% \mathrm{CI}$} \\
\hline & & & LLCI & ULCI \\
\hline \multicolumn{5}{|l|}{ Direct Effect } \\
\hline $\mathrm{PU} \rightarrow \mathrm{IO}$ & 0.17 & 0.02 & 0.13 & 0.21 \\
\hline $\mathrm{PU} \rightarrow \mathrm{IA}$ & -0.10 & 0.08 & -0.25 & 0.05 \\
\hline $\mathrm{PU} \rightarrow \mathrm{IB}$ & -0.08 & 0.06 & -0.21 & 0.04 \\
\hline $\mathrm{IO} \rightarrow \mathrm{IA}$ & 0.43 & 0.17 & 0.10 & 0.76 \\
\hline $\mathrm{IO} \rightarrow \mathrm{IB}$ & -0.19 & 0.14 & -0.46 & 0.09 \\
\hline $\mathrm{IA} \rightarrow \mathrm{IB}$ & 0.72 & 0.04 & 0.64 & 0.79 \\
\hline \multicolumn{5}{|l|}{ Indirect Effect } \\
\hline $\mathrm{PU} \rightarrow \mathrm{IO} \rightarrow \mathrm{IA}$ & 0.07 & 0.03 & 0.02 & 0.13 \\
\hline $\mathrm{PU} \rightarrow \mathrm{IO} \rightarrow \mathrm{IB}$ & -0.03 & 0.02 & -0.08 & 0.02 \\
\hline $\mathrm{PU} \rightarrow \mathrm{IO} \rightarrow \mathrm{IA} \rightarrow \mathrm{IB}$ & 0.05 & 0.02 & 0.01 & 0.09 \\
\hline
\end{tabular}

$\mathrm{N}=525$ observations nested within 105 individuals. The table shows unstandardized estimates. PU $=$ Perceived Uncertainty on COVID-19; $\mathrm{IO}=$ Information Overload; IA = Information Anxiety; IB = Impulsive Buying limited number of existing studies, which provided indirect evidence of the effect of uncertainty on impulsive buying under emergency and crisis situations. For instance, Dawson and Kim (2009) stated that exposure to certain external stimuli will increase the likelihood of impulsive buying. Also, Cakanlar and Nguyen (2019) found that there is a positive relationship between uncertainty and impulsive buying behavior. Our results not only replicated the findings of prior studies concerning the 'dark side' of uncertainty, but also shed light on its temporal influences on stimulating impulsive buying.

Second, the findings of the present study revealed the internal mechanism of influence of the perceived uncertainty on COVID-19 on impulsive buying from the perspective of cognitive-affective units, addressing the necessity of taking into account our insights into the negative sides of Internet information, especially during a public health crisis. Massive Internet information may lead to information overload and information anxiety, thus stimulating individual impulsive buying behavior due to experiencing uncertainty on COVID-19. Following the CPAS theory, we included both individual psychological cognition (information overload) and negative affect (information anxiety) into our research framework, so as to not only enrich the theoretical perspective on impulsive buying, but also broaden the application scope of the CAPS theory in emergency and crisis management (Mischel \& Shoda, 1998; Shoda, Leetiernan, \& Mischel, 2002). Furthermore, little is known about the whole process of how individuals suffered cognitive and affective changes, and made behavioral choices during the COVID-19 pandemic. The results of the present study demonstrated the complete chain-mediating effect of information overload and information anxiety on the relationship between perceived uncertainty on COVID-19 and impulsive buying. Our findings may help researchers to deepen their understanding of the internal psychological mechanisms through which the perceived uncertainty on COVID-19 affects individual impulsive buying; moreover, they may provide a new study perspective to 
explain how impulsive buying is triggered during emergency and crisis situation, and enrich the emergency and crisis management literature.

Third, we employed the ESM design to capture the dynamic effect of the perceived uncertainty on COVID-19 on impulsive buying over time. Timeframe is important to elaborate the influence of the COVID-19 event on shaping individual behavior, due to the "ongoing, dynamic, and time-dependent" nature of this type of emergency events (Beal, Weiss, Barros, $\&$ Mac Dermid, 2005; Morgeson et al., 2015). For example, the likelihood of impulsive buying may have increased in the early days of the emergency event, when the novelty and uncertainty on the COVID-19 were more prominent. However, the majority of previous studies have explored the static relationship between the COVID-19 event and individual emotion and behavior using a between-persons approach, which failed to capture the (intra-individual) fluctuation of the COVID-19 event (e.g., Farooq et al., 2020). Similarly, although previous studies indicated that information overload is positively related to anxiety, the temporal dynamic in this relationship has not been tested (Hwang et al., 2019). Recent calls for a more comprehensive understanding of individual differences in psychological processes emphasized the utility of repeated measures approaches (Bauer, 2011). Static, summary measures of long-past experiences often cannot provide the critical experiential elements of the processes that unfold dynamically over relatively short periods of time (Beal \& Weiss, 2013). The application of the ESM, which collects the dynamic individual data influenced by social situation factors in a "field, real-time" way, allows an in-depth understanding of the relationship between within-person variables (Bolger \& Laurenceau, 2013; Koopman, Lanaj, \& Scott, 2016). As such, by adopting the ESM, our findings clarified the temporal relationship between the perceived uncertainty on COVID-19 and impulsive buying and the internal mechanism on a daily basis.

\section{Practical Implications}

It has become essential and urgent to consider the significant impact of the Internet and social media to investigate public impulsive buying behavior under emergency and crisis situations, such as that of COVID-19. Hence, our study has several practical implications for governments, media workers, and the public.

Improving the media information literacy and using Internet cognitive behavior therapy(I-CBT), to overcome the "infodemic" and reduce impulsive buying. The present study found a positive indirect relationship between information overload and impulsive buying via information anxiety. In the era of Internet, in which information is massively increasing and changing dynamically, every citizen should have a certain media information literacy, so as to overcome information overload and alleviate information anxiety. The public should consciously enhance information immunity, and especially enhance their information discrimination and critical thinking ability. It is necessary to have the basic knowledge and skills necessary for the scientific prevention and control of COVID-19, but also to be vigilant and contain the "anxiety virus" and "rumor virus", so as to reduce the unnecessary impulsive buying caused by anxiety. In addition, it is worthwhile to use online psychological intervention, such as I-CBT, to promote mental health and reduce impulsive buying during COVID-19 as it is part of telemedicine and cost effective (Zhang \& Ho, 2017; Tran et al., 2020b). It is proved that I-CBT, through teaching relaxation techniques and enhancing stress management, can prevent anxiety and mitigate maladaptive coping (e.g. impulsive buying) (Ho, Chee, \& Ho, 2020).

Releasing information on the pandemic and clarifying rumors in time, to relieve social anxiety. Our results show that uncertainty on COVID-19 may lead to information overload, information anxiety and impulsive buying among the public. Thus, the relevant departments of the government should strictly control the sources of the information, actively and timely release authoritative information, try to restore the truth, and reduce the harm and speed of rumors, so as to help the public learn to cope with the uncertainty and variability of the pandemic, and generate a rational cognition on this basis. On the other hand, continuous and standardized public mental health surveys are needed to achieve the purpose of risk prevention and risk avoidance. When information anxiety reaches a critical level, large-scale mass incidents (such as impulsive buying) will be triggered. Establishing a public mental health survey network can allow to observe such a critical change in public information anxiety in advance. Therefore, we can anticipate and actively intervene to relieve emotional stress and keep individuals away from a critical state.

Achieving a benign information interaction and strengthening media responsibility awareness. We found that in emergency and crisis events, a large quantity of either true or false information may lead to the occurrence of mass incidents (such as impulsive buying). For media worker, a pandemic is not only a public health crisis, but also a test of information security. Admittedly, media worker cannot simply address arousing public concern and, at the same time, avoid information anxiety. Only through professional operation, the grasp of norms, and the care of different social groups, can they provide scientific information and a cognitive increment to the audience, which can truly alleviate people's information anxiety and avoid adverse social impacts.

\section{Limitations and Future Research}

Our study has several limitations that should be noted. First, it could not avoid the CMB (Podsakoff et al., 2003). We 
adopted a two-wave daily ESM to collect daily data, which decreased the CMB to a certain degree. However, all variables relied on self-reports, which may have increased the CMB (Scharkow, 2019). Thus, future research may adopt objective data representing impulsive buying, so as to further rule out the CMB. In addition, our study was mainly based on the CAPS theory to introduce relevant psychological mediators. As such, the possibility of other theoretical explanations or variables cannot be ruled out. For example, the public acquire the necessary information through the online platform when confronted with the COVID-19 pandemic (Abeler, Bäcker, Buermeyer, \& Zillessen, 2020). How information acquired shapes users' attitudes and behavior depends on the informational and technical characteristics of the platforms (Xiao \& Mou, 2019). Thus, in the future, we can consider introducing informational and technical characteristics variables, such as information transparency, information source credibility and media richness, to further explore the internal mechanism of impulsive buying under emergency and crisis situations. Third, the causal relationships between our two mediators cannot be inferred, even though we conducted a two-wave ESM design. There is still the possibility of a reverse causal effect, and an experimental design may be the proper way to support causal results in the future.

\section{Conclusion}

Based on the CAPS theory, our study explored for the first time how the daily perceived uncertainty on COVID-19 stimulated individual daily impulsive buying via the chainmediating mechanism of daily information overload and daily information anxiety, from the perspective of cognitionaffective units. The results of our data analysis support the hypotheses proposed in the present study. Namely, the daily perceived uncertainty on COVID-19 had a significant positive impact on daily impulsive buying, with daily information overload and daily information anxiety playing a complete chain-mediating role. The results of the present study provide important insights to the emergency and crisis management literature; in fact, although previous studies investigated the static relationship between uncertainty and impulsive buying, to date a discussion of their internal mechanism was lacking (Cakanlar \& Nguyen, 2019; Farooq et al., 2020). As such, the present study uncovered the important dynamic effect and the internal mechanism of the perceived uncertainty on COVID19 on impulsive buying.

Acknowledgments This research was supported by the National Natural Science Foundation of China (Grants No. 71772052) and the Fundamental Research Funds awarded to the third author.
Data Availability Statements The datasets generated during and/or analyzed during the current study are available from the corresponding author on reasonable request.

\section{Compliance with Ethical Standards}

All procedures performed in studies involving human participants were in accordance with the ethical standards of the institutional and/or national research committee and with the 1964 Helsinki Declaration and its later amendments or comparable ethical standards.

Conflict of Interest The authors declare that they have no conflict of interests.

Informed Consent Informed consent was obtained from all individual participants included in the study.

Ethics Approval Statement I would like to declare on behalf of my coauthors that the work described was original research that has not been published previously, and not under consideration for publication elsewhere, in whole or in part. All the authors listed have approved the manuscript that is enclosed.

\section{References}

Abeler, J., Bäcker, M., Buermeyer, U., \& Zillessen, H. (2020). COVID19 contact tracing and data protection can go together. JMIR mHealth and uHealth, 8(4), e19359. https://doi.org/10.2196/19359.

Ahmad, A. R., \& Murad, H. R. (2020). The impact of social media on panic during the COVID-19 pandemic in Iraqi Kurdistan. Journal of Medical Internet Research, 22(5), e19556. https://oi.org/10.2196/ 19556.

Aparecida Lehmann, T., Krug, J., \& Falaster, C. D. (2019). Consumer purchase decision: Factors that influence impulsive purchasing. REMark: Revista Brasileira de Marketing, 18(4), 196-219. https:// doi.org/10.5585/remark.v18i4.13345.

Arnold, M. B. (1960). Emotion and personality. American Journal of Psychology, 3, 4662-4671.

Bandyopadhyay, N. (2016). The role of self-esteem, negative affect and normative influence in impulsive buying. Marketing Intelligence \& Planning, 34(4), 523-539. https://doi.org/10.1108/mip-02-20150037.

Bauer, D. J. (2011). Evaluating individual differences in psychological processes. Current Directions in Psychological Science, 20, 115118. https://doi.org/10.1177/0963721411402670.

Bawden, D., \& Robinson, L. (2009). The dark side of information: Overload, anxiety and other paradoxes and pathologies. Journal of Information Science, 35(2), 180-191. https://doi.org/10.1177/ 0165551508095781.

Beal, D. J., \& Weiss, H. M. (2013). The episodic structure of life at work. In A. B. Bakker \& K. Daniels (Eds.), A day in the life of a happy worker (pp. 8-24). London: Psychology Press.

Beal, D. J., Weiss, H. M., Barros, E., \& Mac Dermid, S. M. (2005). An episodic process model of affective influences on performance. Journal of Applied Psychology, 90(6), 1054-1068. https://doi.org/ 10.1037/0021-9010.90.6.1054.

Bellini, S., Cardinali, M. G., \& Grandi, B. (2017). A structural equation model of impulse buying behaviour in grocery retailing. Journal of Retailing and Consumer Services, 36, 164-171. https://doi.org/10. 1016/j.jretconser.2017.02.001.

Benselin, J. C., \& Ragsdell, G. (2016). Information overload: The differences that age makes. Journal of Librarianship and Information 
Science, 48(3), 284-297. https://doi.org/10.1177/ 0961000614566341.

Bliese, P. D., Maltarich, M. A., \& Hendricks, J. L. (2018). Back to basics with mixedeffects models: Nine take-away points. Journal of Business and Psychology, 33(1), 1-23. https://doi.org/10.1007/ s10869-017-9491-z.

Bolger, N., \& Laurenceau, J. P. (2013). Intensive longitudinal methods: An introduction to diary and experience sampling research. New York: Guilford Press.

Bratko, D., Butkovic, A., \& Bosnjak, M. (2013). Twin study of impulsive buying and its overlap with personality. Journal of Individual Differences, 34, 8-14. https://doi.org/10.1027/1614-0001/a000091.

Brislin, R. W. (1980). Translation and content analysis of oral and written material. In H. C. Triandis \& J. W. Berry (Eds.), Handbook of crosscultural psychology (pp. 389-444). Boston, MA: Allyn \& Bacon.

Cakanlar, A., \& Nguyen, T. (2019). The influence of culture on impulse buying. Journal of Consumer Marketing, 36(1), 12-23. https://doi. org/10.1108/jcm-03-2017-2139.

Cao, X., \& Sun, J. (2018). Exploring the effect of overload on the discontinuous intention of social media users: An S-O-R perspective. Computers in Human Behavior, 81, 10-18. https://doi.org/10.1016/ j.chb.2017.11.035.

Cervone, D. (2005). Personality architecture: Within-person structures and processes. Annual Review of Psychology, 56, 423-452. https:// doi.org/10.1146/annurev.psych.56.091103.070133.

Chen, W., \& Lee, K. H. (2013). Sharing, liking, commenting, and distressed? the pathway between Facebook interaction and psychological distress. Cyber psychology Behavior \& Social Networking, 16(10), 728-734. https://doi.org/10.1089/cyber.2012.0272.

Chongqing Evening News. (2020). Female white-collar workers rushed to the news to cause continuous insomnia. Resource document. http://www.chinanews.com/jk/2020/03-20/9132107.shtml. Accessed 20 March 2020

Chow, E., \& Elkind, J. (2005). Hurricane Katrina and US energy security. Survival, 47(4), 145-160. https://doi.org/10.1080/ 00396330500433449.

D'Antoni Jr., J. S., \& Shenson, H. L. (1973). Impulse buying revisited: A behavioral typology. Journal of Retailing, 49(1), 63-76.

Dawson, S., \& Kim, M. (2009). External and internal trigger cues of impulse buying online. Direct Marketing: An International Journal, 3(1), 20-34. https://doi.org/10.1108/17505930910945714.

Deng, S., Wang, W., Xie, P., Chao, Y., \& Zhu, J. (2020). Perceived severity of COVID-19 and post-pandemic consumption willingness: The roles of boredom and sensation-seeking. Frontiers in Psychology, 11. https://doi.org/10.3389/fpsyg.2020.567784.

Du, D., Derks, D., \& Bakker, A. B. (2018). Daily spillover from family to work: A test of the work-home resources model. Journal of Occupational Health Psychology, 23(2), 237-247. https://doi.org/ 10.1037/ocp0000073.

Eppler, M. J., \& Mengis, J. (2004). The concept of information overload: A review of literature from organization science, accounting, marketing, MIS, and related disciplines. The Information Society, 20(5), 325-344. https://doi.org/10.1080/01972240490507974.

Farooq, A., Laato, S., \& Akam, I. (2020). Impact of online information on self-isolation intention during the COVID-19 pandemic: Crosssectional study. Journal of Medical Internet Research, 22(5), e19128. https://doi.org/10.2196/19128.

Fischer, R., Karl, J, A., Bortolini, T., Zilberberg, M., Robinson, K., Rabelo, A, L, A., et al.(2020). Rapid review and meta-metaanalysis of self-guided interventions to address anxiety, depression and stress during COVID-19 social distancing. Frontiers in Psychology, 11. https://doi.org/10.3389/fpsyg.2020.563876.

Fornell, C., \& Larcker, D. (1981). Evaluating structural equation models with unobservable variables and measurement error. Journal of
Marketing Research, 18(1), 39-50. https://doi.org/10.1177/ 002224378101800104.

Hair, J. F., Black, W. C., Babin, B. J., \& Anderson, R. E. (2010). Multivariate data analysis (7th ed). Upper Saddle River, NJ: Prentice Hall.

He, H., Kukar-Kinney, M., \& Ridgway, N. M. (2018). Compulsive buying in China: Measurement, prevalence, and online drivers. Journal of Business Research, 91, 28-39. https://doi.org/10.1016/j.jbusres. 2018.05.023.

Heylighen, F. (2002). Complexity and information overload in society: why increasing efficiency leads to decreasing control. Technological Frecasting and Social Change, 81(9), 129-135.

Ho, C. S. H., Chee, C. Y. I., \& Ho, R. C. M. (2020). Mental health strategies to combat the psychological impact of coronavirus disease 2019 (COVID-19) beyond paranoia and panic. Annals Academy of Medicine Singapore, 49(3), 155-160.

Horton, R. O. (2020). 2019-nCoV_-“A desperate plea”. Lancet, 395, 400-124. https://doi.org/10.1080/15332861.2016.1148971.

Hua, J., \& Shaw, R. (2020). Corona virus (COVID-19) "Infodemic" and emerging issues through a data Lens: The case of China. International Journal of Environmental Research and Public Health, 17, 2309. https://doi.org/10.3390/ijerph17072309.

Huang, Y., \& Zhao, N. (2020). Generalized anxiety disorder, depressive symptoms and sleep quality during COVID-19 outbreak in China: A web-based cross-sectional survey. Psychiatry Research, 288(112954), 112954. https://doi.org/10.1016/j.psychres.2020. 112954.

Hwang, M, Y., Hong, J, C., Tai, K, H., Chen, J, T., \& Gouldthorp, T. (2019). The relationship between the online social anxiety, perceived information overload and fatigue, and job engagement of civil servant LINE users. Government Information Quarterly, 101423. https://doi.org/10.1016/j.giq.2019.101423.

Koopman, J., Lanaj, K., \& Scott, B. A. (2016). Integrating the bright and dark sides of OCB: A daily investigation of the benefits and costs of helping others. Academy of Management Journal, 59(2), 414-435. https://doi.org/10.5465/amj.2014.0262.

LaRose, R., Connolly, R., Lee, H., Li, K., \& Hales, K. D. (2014). Connection overload? A cross cultural study of the consequences of social media connection. Information Systems Management, 31, 59-73. https://doi.org/10.1080/10580530.2014.854097.

Lavelle, J. J., Rupp, D. E., \& Brockner, J. (2007). Taking a multifoci approach to the study of justice, social exchange, and citizenship behavior: The target similarity model. Journal of Management, 33(6), 841-866. https://doi.org/10.1177/0149206307307635.

Lazarus, R. S., \& Folkman, S. (1984). Stress, appraisal, and coping. New York: NY, Springer Publishing.

Le, H. T., Nguyen, D. N., Beydoun, A. S., Le, X. T. T., Nguyen, T. T., Pham, Q. T., et al. (2020). Demand for health information on COVID-19 among Vietnamese. International Journal of Environmental Research and Public Health, 17(12), 4377. https:// doi.org/10.3390/ijerph17124377.

Lee, J., \& Pee, L. G. (2015). The relationship between online trust and distrust in business: Testing mutual causality from a cognitiveaffective personality system theory. Asia Pacific Journal of Information Systems, 25(3), 500-518. https://doi.org/10.14329/ apjis.2015.25.3.500.

Lee, A. R., Son, S. M., \& Kim, K. K. (2016). Information and communication technology overload and social networking service fatigue: A stress perspective. Computers in Human Behavior, 55, 51-61. https://doi.org/10.1016/j.chb.2015.08.011.

Liu, C.-L. (2014). Ontological subscription and blocking system that alleviates information overload in social blogs. Knowledge-Based Systems, 63, 33-45. https://doi.org/10.1016/j.knosys.2014.03.005.

Liu, P., He, J., \& Li, A. (2019). Upward social comparison on social network sites and impulse buying: A moderated mediation model 
of negative affect and rumination. Computers in Human Behavior, 96, 133-140. https://doi.org/10.1016/j.chb.2019.02.003.

Lucas, M., \& Koff, E. (2017). Body image, impulse buying, and the mediating role of negative affect. Personality \& Individual Differences, 105, 330-334. https://doi.org/10.1016/j.paid.2016.10. 004.

Matthes, J., Karsay, K., Schmuck, D., \& Stevic, A. (2019). "Too much to handle" impact of mobile social networking sites on information overload, depressive symptoms, and well-being. Computers in Human Behavior, 105, 106217. https://doi.org/10.1016/j.chb.2019. 106217.

Mccormick, B. W., Reeves, C. J., Downes, P. E., Li, N., \& Ilies, R. (2020). Scientific contributions of within-person research in management: Making the juice worth the squeeze. Journal of Management, 46, 321-350. https://doi.org/10.1177/ 0149206318788435.

Mischel, W., \& Shoda, Y. (1995). A cognitive-affective system theory of personality: Reconceptualizing situations, dispositions, dynamics, and invariance in personality structure. Psychological Review, 102, 246-268. https://doi.org/10.1037/0033-295x.102.2.246.

Mischel, W., \& Shoda, Y. (1998). Reconciling processing dynamics and personality dispositions. Annual Review of Psychology, 49, 229258. https://doi.org/10.1146/annurev.psych.49.1.229.

Misra, S., \& Stokols, D. (2012). Psychological and health outcomes of perceived information overload. Environment and Behavior, 44(6), 737-759. https://doi.org/10.1177/0013916511404408.

Mohan, G., Sivakumaran, B., \& Sharma, P. (2013). Impact of store environment on impulse buying behavior. European Journal of Marketing, 47, 1711-1732. https://doi.org/10.1108/ejm-03-20110110.

Moors, A., Ellsworth, P. C., Scherer, K. R., \& Frijda, N. H. (2013). Appraisal theories of emotion: State of the art nad future development. Emotion Review, 2, 119-124. https://doi.org/10.1177/ 1754073912468165.

Morgeson, F. P. (2005). The external leadership of self-managing teams: Intervening in the context of novel and disruptive events. Journal of Applied Psychology, 90(3), 497-508. https://doi.org/10.1037/00219010.90.3.497.

Morgeson, F. P., Mitchell, T. R., \& Liu, D. (2015). Event system theory: An event-oriented approach to the organizational sciences. Academy of Management Review, 40(4), 515-537. https://doi.org/10.5465/ amr.2012.0099.

Müller, A., Mitchell, J. E., Crosby, R. D., Cao, L., Johnson, J., Claes, L., \& de Zwaan, M. (2012). Mood states preceding and following compulsive buying episodes: An ecological momentary assessment study. Psychiatry Research, 200(2), 575-580. https://doi.org/10. 1016/j.psychres.2012.04.015.

Muthén, L. K., \& Muthén, B. O. (2010). Mplus user's guide. Los Angeles, CA: Author.

Nagar, K. (2016). Drivers of E-store patronage intentions: Choice overload, internet shopping anxiety, and impulse purchase tendency. Journal of Internet Commerce, 15(2), 97-124. https://doi.org/10. 1080/15332861.2016.1148971.

People's Daily of China. (2020). The novel coronavirus can be inhibited by Chinese patent medicine Shuanghuanglian oral liquid. Resource document. http://search.people.com.cn/cnpeople/news/ getNewsResult.jsp. Accessed 31 Jan 2020.

Ping, Z.,. A. (2013). The affective response model: Theoretic framework of affective concepts and their relationships in the ICT context. MIS Quarterly, (1), 247-274. https://doi.org/10.25300/misq/2013/37.1. 11.

Podsakoff, P. M., MacKenzie, S. B., Lee, J. Y., \& Podsakoff, N. P. (2003). Common method biases in behavioral research: A critical review of the literature and recommended remedies. Journal of Applied Psychology, 88(5), 879-903. https://doi.org/10.1037/ 0021-9010.88.5.879.
Preacher, K. J., Zyphur, M. J., \& Zhang, Z. (2010). A general multilevel SEM framework for assessing multilevel mediation. Psychological Methods, 15(3), 209-233. https://doi.org/10.1037/a0020141.

Primack, B. A., Shensa, A., Escobar-Viera, C. G., Barrett, E. L., Sidani, J. E., Colditz, J. B., \& James, A. E. (2017). Use of multiple social media platforms and symptoms of depression and anxiety: A nationally-representative study among U.S. young adults. Computers in Human Behavior, 69, 1-9. https://doi.org/10.1016/j. chb.2016.11.013.

Qin, X., Huang, M. P., Johnson, R. E., Hu, Q. J., \& Ju, D. (2018). The short-lived benefits of abusive supervisory behavior for actors: An investigation of recovery and work engagement. Academy of Management Journal, 61(5), 1951-1975. https://doi.org/10.5465/ amj.2016.1325.

Raudenbush, S. W., Bryk, A. S., Cheong, Y. F., Congdon, R. T., \& du Toit, M. (2011). HLM 7: Hierarchical linear and nonlinear modeling. Chicago, IL: Scientific Software International.

Remuzzi, A., \& Remuzzi, G. (2020). COVID-19 and Italy: What next? The Lancet, 395(10231), 1225-1228. https://doi.org/10.1016/ S0140-6736(20)30627-9.

Roesch, S. C., Aldridge, A. A., Stocking, S. N., Villodas, F., Leung, Q., Bartley, C. E., \& Black, L. J. (2010). Multilevel factor analysis and structural equation modeling of daily diary coping data: Modeling trait and state variation. Multivariate Behavioral Research, 45(5), 767-789. https://doi.org/10.1080/00273171.2010.519276.

Rook, D. W. (1987). The buying impulse. Journal of Consumer Research, 14(2), 189-199.

Rook, D. W., \& Fisher, R. J. (1995). Normative influences on impulsive buying behavior. Journal of Consumer Research, 22(3), 305-313. https://doi.org/10.1086/209452.

Scharkow, M. (2019). The reliability and temporal stability of selfreported media exposure: A meta-analysis. Communication Methods and Measures, 13(3), 198-211. https://doi.org/10.1080/ 19312458.2019.1594742.

Schmitt, J. B., Debbelt, C. A., \& Schneider, F. M. (2017). Too much information? Predictors of information overload in the context of online news exposure. Information, Communication \& Society, 21(8), 1151-1167. https://doi.org/10.1080/1369118X.2017. 1305427.

Shannon, C. E. (1948). A mathematical theory of communication. The Bell System Technical Journal, 27, 379-423.

Sharma, M., Yadav, K., Yadav, N., \& Ferdinand, K. C. (2017). Zika virus pandemic - Analysis of Facebook as a social media health information platform. American Journal of Infection Control, 45(3), 301302. https://doi.org/10.1016/j.ajic.2016.08.022.

Shoda, Y., Leetiernan, S., \& Mischel, W. (2002). Personality as a dynamical system: Emergence of stability and distinctiveness from intraand interpersonal interactions. Personality and Social Psychology Review, 6(4), 316-325. https://doi.org/10.1207/ s15327957pspr0604 06 .

Siemer, M. J., Gross, J., \& Mauss, I. (2007). Same situation and different emotions: How appraisals shape our emotions. Emotion, 7(3), 592600. https://doi.org/10.1037/1528-3542.7.3.592.

Sim, K., Chua, H. C., Vieta, E., \& Fernandez, G. (2020). The anatomy of panic buying related to the current COVID-19 pandemic. Psychiatry Research, 113015, 113015. https://doi.org/10.1016/j.psychres. 2020.113015.

Smith, K., Ostinelli, E., \& Cipriani, A. (2020). Covid-19 and mental health: A transformational opportunity to apply an evidence-based approach to clinical practice and research. Evidence Based Mental Health, 300155. https://doi.org/10.1136/ebmental-2020-300155.

Sommariva, S., Vamos, C., Mantzarlis, A., Đào, L. U.-L., \& Martinez Tyson, D. (2018). Spreading the (fake) news: Exploring health messages on social media and the implications for health professionals using a case study. American Journal of Health Education, 49(4), 246-255. https://doi.org/10.1080/19325037.2018.1473178. 
Sonnentag, S. (2012). Time in organizational research: Catching up on a long neglected topic in order to improve theory. Organizational Psychology Review, 2(4), 361-368. https://doi.org/10.1177/ 2041386612442079.

Stern, H. (1962). The significance of impulse buying today. The Journal of Marketing, 26(2), 59-62. https://doi.org/10.2307/1248439.

Swar, B., Hameed, T., \& Reychav, I. (2017). Information overload, psychological ill-being, and behavioral intention to continue online health information search. Computers in Human Behavior, 70(5), 416-425. https://doi.org/10.1016/j.chb.2016.12.068.

Thatcher, J. B., \& Perrewe, P. L. (2002). An empirical examination of individual traits as antecedents to computer anxiety and computer self-efficacy. MIS Quarterly, 26(4), 381-396. https://doi.org/10. $2307 / 4132314$.

Thomas, A. G., \& Monica, S.-S. (2002). Bioterrorism and the people: How to vaccinate a city against panic. Clinical Infectious Diseases, 34(2), 217-223. https://doi.org/10.1086/338711.

Tran, B. X., Dang, A. K., Thai, P. K., Le, H. T., Le, X. T. T., Do, T. T. T., et al. (2020a). Coverage of health information by different sources in communities: Implication for COVID-19 epidemic response. International Journal of Environmental Research and Public Health, 17(10), 3577. https://doi.org/10.3390/ijerph17103577.

Tran, B. X., Hoang, M. T., Vo, L. H., Le, H. T., Nguyen, T. H., Vu, G. T., et al. (2020b). Telemedicine in the COVID-19 pandemic: Motivations for integrated, interconnected, and community-based health delivery in resource-scarce settings? Frontiers in Psychiatry, 11, 564452. https://doi.org/10.3389/fpsyt.2020.564452.

Valence, G., D’Astous, A., \& Fortier, L. (1988). Compulsive buying: Concept and measurement. Journal of Consume Policy, 11(4), 419-433. https://doi.org/10.1007/bf00411854.

Verplanken, B., Herabadi, A. G., Perry, J. A., \& Silvera, D. H. (2005). Consumer style and health: The role of impulsive buying in unhealthy eating. Psychology \& Health, 20(4), 429-441. https://doi. org/10.1080/08870440412331337084.

Vohs, K. D., \& Faber, R. J. (2007). Spent resources: Self-regulatory resource availability affects impulse buying. Journal of Consumer Research, 33, 537-547.

Wang, C., Peter, W. H., Frederick, G. H., \& George, F. G. (2020a). A novel coronavirus outbreak of global health concern. Lancet, 395, 470-473. https://doi.org/10.1016/s0140-6736(20)30185-9.

Wang, C., Pan, R., Wan, X., Tan, Y., Xu, L., Ho, C. S., \& Ho, R. C. (2020c). Immediate psychological responses and associated factors during the initial stage of the 2019 coronavirus disease (COVID-19) pandemic among the general population in China. International Journal of Environmental Research and Public Health, 17(5). https://doi.org/10.3390/ijerph17051729.
Wang, C., Chudzicka-Czupała, A., Grabowski, D., Pan, R., Adamus, K., Wan, X., Hetnał, M., Tan, Y., Olszewska-Guizzo, A., Xu, L., McIntyre, R. S., Quek, J., Ho, R., \& Ho, C. (2020b). The association between physical and mental health and face mask use during the COVID-19 pandemic: A comparison of two countries with different views and practices. Frontiers in Psychiatry, 11, 901. https://doi. org/10.3389/fpsyt.2020.569981.

Wang, C., Pan, R., Wan, X., Tan, Y., Xu, L., McIntyre, R. S., Choo, F. N., Tran, B., Ho, R., Sharma, V. K., \& Ho, C. (2020d). A longitudinal study on the mental health of general population during the COVID-19 pandemic in China. Brain, Behavior, and Immunity., 87, 40-48. https://doi.org/10.1016/j.bbi.2020.04.028.

Wurman, R. S. (1989). Information anxiety. Bantam Doubleday Dell Publishing Group Inc.

Xiang, Y. T., Yang, Y., Li, W., Zhang, L., Zhang, Q., Cheung, T., \& Ng, C. H. (2020). Timely mental health care for the 2019 novel corona virus outbreak is urgently needed. Lancet Psychiatry, 7(3), 228229. https://doi.org/10.1016/s2215-0366(20)30046-8.

Xiao, L., \& Mou, J. (2019). Social media fatigue-technological antecedents and the moderating roles of personality traits: The case of WeChat. Computers in Human Behavior, 101, 297-310. https:// doi.org/10.1016/j.chb.2019.08.001.

Xiong, J., Lipsitz, O., Nasri, F., Lui, L. M. W., Gill, H., Phan, L., ChenLi, D., Iacobucci, M., Ho, R., Majeed, A., \& McIntyre, R. S. (2020). Impact of COVID-19 pandemic on mental health in the general population: A systematic review. Journal of Affective Disorders., 277, 55-64. https://doi.org/10.1016/j.jad.2020.08.001.

Yao, Z., Zhang, X., Luo, J., \& Huang, H. (2020). Offense is the best defense: The impact of workplace bullying on knowledge hiding. Journal of Knowledge Management., 24, 675-695. https://doi.org/ 10.1108/JKM-12-2019-0755.

Yi, S. (2012). Shame-proneness as a risk factor of compulsive buying. Journal of Consume Policy, 35(3), 393-410. https://doi.org/10. 1007/s10603-012-9194-9.

Zarocostas, J. (2020). How to fight an infodemic. The Lancet, 395(10225), 676. https://doi.org/10.1016/S0140-6736(20)30461-X.

Zhang, M. W. B., \& Ho, R. C. M. (2017). The cost effective solution for internet cognitive behavioral therapy (I-CBT) interventions. Technology and Health Care, 25(1), 163-165. https://doi.org/10. 3233/THC-161261.

Publisher's Note Springer Nature remains neutral with regard to jurisdictional claims in published maps and institutional affiliations. 